\title{
Drainage or nondrainage for single-level anterior cervical discectomy with fusion and plating
}

\section{Pengfei Li}

Hospital

Dean Chou

Hospital

\section{Yuqiang Wang}

Hospital

Limin Wang

Hospital

Ganggang Zhang

Hospital

Shuhao Zhang

Hospital

Yao Zhao

Hospital

Tianchen Ruan

Hospital

\section{Yingjie Xiong}

Hospital

\section{Landa Shi}

Hospital

Yilin Liu ( $\nabla$ zzu0101@126.com )

Hospital https://orcid.org/0000-0002-4792-4361

\section{Research article}

Keywords: Enhanced recovery after surgery, Single-level, Anterior cervical discectomy with fusion and plating, Natural pressure drainage, Symptomatic epidural hematoma

Posted Date: October 4th, 2019

DOI: https://doi.org/10.21203/rs.2.15787/v1

License: (9) This work is licensed under a Creative Commons Attribution 4.0 International License. Read Full License 
Page $2 / 18$ 


\section{Abstract}

Background Currently, conventional placement of natural pressure drainage after single-level anterior cervical discectomy with fusion and plating (ACDF) is used clinically to prevent complications such as symptomatic epidural hematoma and incision infection. Nevertheless, a literature review reported that there is no uniform standard for whether to place drainage after single-level ACDF surgery, and comparative studies on this subject are rare.

Methods A prospective study of 100 patients who underwent single-level ACDF from January 2017 to June 2018 and met the selection criteria were randomly divided into the control group (45 patients with drainage after surgery) and the study group (48 patients without drainage after surgery). The same types of preoperative preparation, surgical technique and postoperative management were used in the two groups. The perioperative indicators, postoperative clinical efficacy and complications were compared between the two groups.

Results The preoperative and postoperative Japanese Orthopaedic Association (JOA) scores, Visual Analogue Scale (VAS) scores and Neck Dysfunction Index (NDI) scores in the two groups were significantly different $(P<0.05)$. The length of hospital stay in the study group was significantly shorter than that in the control group $(P<0.05)$. There were no significant differences in postoperative fever, surgical site infection, symptomatic epidural hematoma, rate of incision healing, or complications between the two groups $(P>0.05)$.

Conclusions The safety and clinical outcome of patients with drainage after single-level ACDF were consistent with those of nondrainage patients. Additionally, nondrainage after single-level ACDF resulted in a decreased length of hospital stay and lessened the associated expenses.

\section{Background}

Cervical spondylosis is a common disease in spinal surgery. When patients have symptoms and signs of spinal cord or nerve root compression caused by single-level cervical disc degeneration and when conservative treatment is ineffective, single-level anterior cervical discectomy with fusion and plating (ACDF) is a common surgical procedure [1,2]. At present, natural pressure drainage is routinely placed to prevent hematoma formation and to avoid spinal cord compression or incision infection $[3,4]$. However, some studies have suggested that indwelling drainage after spinal surgery can reduce swelling of the operation area and may also lead to increased hemoglobin loss after operation; additionally, whether the drainage is placed has no significant effect on incision infection, hematoma, wound dehiscence or reoperation [5]. Moreover, the incision drainage volume after single-level ACDF is low, and with the advancement of medical technology, enhanced recovery after surgery (ERAS) in the perioperative period has been continuously improved. In recent years, we have noticed that the incidence of symptomatic epidural 
hematoma in patients with single-level ACDF is extremely low, the drainage volume is very small, and the healing of the anterior cervical drainage hole is slower than that of the surgical incision, thus prolonging the hospitalization time. Therefore, we aim to assess whether drainage placement is necessary in single-level ACDF surgery. There is no uniform standard for drainage placement after single-level ACDF; there are no literature reviews, and comparative studies are lacking. Aiming to provide a reference for whether to place drainage after surgery, we compared the safety and clinical outcome of drainage placement and nondrainage after single-level ACDF in the study.

\section{Methods}

\section{Patient population and indications}

From January 2017 to June 2018, a total of 100 patients met the standard criteria and underwent single-level ACDF. Among them, 7 patients were lost to follow-up (5 patients in the control group and 2 patients in the study group), and a total of 93 patients (mean age, $54.1 \mathrm{yr}$; range, 39-70 yr) consisting of 54 males and 39 females obtained complete follow-up data. There was 1 patient with C2-C3 decompression, 8 patients with C3-C4 decompression, 31 patients with C4-5 decompression, 36 patients with C5-6 decompression, and 17 patients with C6-C7 decompression. According to whether postoperative drainage placement occurred, patients were randomly divided into the control group (45 patients with natural pressure drainage after the operation) and the study group (48 patients without drainage after the operation). There were no significant differences in mean age, sex, surgical segment, comorbidities, or body mass index (BMI) between the two groups ( $p>0.05$, Table 1), which were comparable. Follow-up was performed 3 months and 6 months after surgery, and the subsequent follow-up examinations were performed at 6-month intervals. The overall follow-up period of the patients was 12 months.

The inclusion criteria were as follows: (1) the symptoms and signs of the patients were consistent with those of cervical disc degeneration and involved a single segment; (2) cervical spine radiography, CT, and MRI showed intervertebral disc degeneration and herniation; and (3) patients underwent single-level ACDF. The exclusion criteria were a history of cervical spine surgery; the involvement of two or more segments; coagulopathy; thrombocytopenia; deep venous thrombosis (DVT); a combination of cervical spine trauma and any serious general illness (e.g., heart failure). 
Table 1 Patient demographic data

\begin{tabular}{|c|c|c|c|}
\hline Variable & $\begin{array}{l}\text { ACDF (with drainage) } \\
\text { Group }\end{array}$ & $\begin{array}{l}\text { ACDF (without drainage) } \\
\text { Group }\end{array}$ & $\begin{array}{cc}\text { Test } & P \\
\text { Value } & \end{array}$ \\
\hline & $(\mathrm{N}=45)$ & $(\mathrm{N}=48)$ & \\
\hline$\overline{\text { Age }(\text { mean } \pm S D)}$ & $54.41 \pm 7.25$ & $53.80 \pm 8.01$ & $0.226 \quad 0.822$ \\
\hline Sex $(n)$ & & & $\mathrm{C} \square=0.0030 .957$ \\
\hline Male & 26 & 28 & \\
\hline Female & 19 & 20 & \\
\hline Operative level & & & $\mathrm{C} \square=0.0340 .853$ \\
\hline $\mathrm{C} 2-\mathrm{C} 3$ & 1 & 0 & \\
\hline $\mathrm{C} 3-\mathrm{C} 4$ & 4 & 4 & \\
\hline C4-C5 & 14 & 17 & \\
\hline C5-C6 & 17 & 19 & \\
\hline C6-C7 & 9 & 8 & \\
\hline Patients with diabetes & 7 & 8 & $C \square=0.0210 .884$ \\
\hline $\begin{array}{l}\text { Patients with } \\
\text { hypertension }\end{array}$ & 10 & 12 & $C \square=0.0990 .753$ \\
\hline Active smokers & 13 & 12 & $\mathrm{C} \square=0.1790 .672$ \\
\hline Active drinkers & 8 & 6 & $C \square=0.5060 .477$ \\
\hline BMI $\left(\mathrm{kg} / \mathrm{m}^{2}\right)$ & $23.08 \pm 1.86$ & $23.46 \pm 1.67$ & 0.6730 .505 \\
\hline
\end{tabular}

\section{Perioperative preparation}

The patients discontinued anticoagulant and antiplatelet drugs during the perioperative period, and preoperative aspirin was stopped for more than 7 days [6]. Fasting blood glucose during the perioperative period in diabetic patients was controlled between 5.56 and $10.00 \mathrm{mmol} / \mathrm{L}$ [7]. Systolic blood pressure was reduced to 80 90 $\mathrm{mmHg}$ or mean arterial blood pressure to 50 65 mmHg; in patients with hypertension, arterial pressure should be reduced to $70 \%$ of the original mean arterial pressure during surgery $[8,9]$. Arterial pressure was monitored and adjusted according to the surgical situation [10]. The postoperative arterial pressure was controlled at 90 140 $\mathrm{mmHg}$. Intravenous antibiotics were administered regularly 30 min before surgery. 


\section{Surgical procedure}

The operative procedures for ACDF have been well described in previous reports [11]. In addition, decompression and intraspinal hemostasis were performed with the aid of a microscope, and bipolar coagulation was used for intraspinal manipulation. For the discectomy and plate internal fixation procedures, cages (Fidji cervical cage, Zimmer, Bordeaux, France) and semiconstrained plating systems (Atlantis; Medtronic Sofamor Danek, Memphis, TN, USA) were used. Medical silicone drainage was placed in the control group, the distal end of the drainage tube was placed in the inner layer of the deep fascia, and the external portion of the drainage tube was connected to a disposable drainage bag with an anti-backflow valve. Drainage was not placed in the study group. Finally, the incision was sutured layer by layer, and the surface of the incision was wrapped with a sterile dressing. After the operation, all patients were immobilized in a cervical collar for 4 weeks.

\section{Postoperative management}

Breathing, drainage and incision dressings were observed closely after the operation, and patients were prevented from developing severe cough. Attention was paid to fixing the neck when moving the patient in order to prevent bleeding from the wound caused by excessive neck movement. The tracheotomy package was routinely prepared at the bedside. Once postoperative bleeding occurred, the sutures and hematoma were removed immediately and sent to the operating room for exploration and hemostasis. During drainage indwelling, placing pressure on the drainage tube was avoided, and the drainage tube was kept unobstructed. The drainage volume and characteristics of the incision within 24 hours were recorded. And the drainage removal standard was that the drainage volume of the incision was less than $50 \mathrm{ml}$ within 24 hours.

\section{Outcome assessment}

The collected data included age, sex, surgical segments, comorbidities, BMI, smoking history, drinking history, operation time, intraoperative blood loss, hospital stay, postoperative drainage volume, postoperative fever (axillary temperature $\geq 38.5^{\circ} \mathrm{C}$ ), surgical site infection (divided into superficial infection and deep infection, with the fascia layer as the boundary), symptomatic epidural hematoma (postoperative dyspnea and/or hypoesthesia and/or decreased muscle strength), rate of incision healing and short-term complications (dysphagia, hoarseness, etc.). The JOA scoring system was used to evaluate 
neurological status, the NDI scoring system was used to assess neck function, and the degree of pain was scored using the VAS.

\section{Statistical analysis}

SPSS for Windows Version 21.0 K (SPSS, Chicago, IL) was used for the analysis. Intergroup comparisons were made using a t test or Pearson chi-square test (Fisher's exact test). Comparisons of clinical outcomes before and after surgery in each group were made using paired t-tests. The comparisons of age, BMI and clinical efficacy between the groups were performed using the independent sample t-test or Wilcoxon signed rank test. Values of $P<0.05$ were considered statistically significant.

\section{Results}

\section{Perioperative index}

The lengths of hospital stay were $8.59 \pm 1.28$ and $7.03 \pm 1.04 \mathrm{~d}$ in the control and study groups, respectively. There was a significant difference between the two groups $(P<0.001$, Table 2). The patients in the ACDF (without drainage) group had a shorter hospital stay than patients in the drainage group. However, there was no significant difference between the two groups in terms of the operation time and intraoperative blood loss $(P>0.05)$. In the control group, 2 patients (4.4\%) had fever, and 1 patient (2.2\%) had superficial incision infection; in the study group, there were 3 patients (6.3\%) with fever and 2 patients (4.2\%) with superficial incision infection. There was no significant difference between postoperative fever and superficial incision infection $(P>0.05)$. In addition, the mean drainage volume of the control group was $3.41 \pm 0.96 \mathrm{ml}$, with a range of 3 to $5 \mathrm{ml}$. No deep incision infection occurred in either group after the operation, and the rate of incision healing in both groups was $100 \%$. 
Table 2 Comparison of perioperative conditions between the two groups

\begin{tabular}{|c|c|c|c|c|}
\hline \multirow[t]{2}{*}{ Variable } & $\begin{array}{c}\text { ACDF (with } \\
\text { drainage) Group }\end{array}$ & $\begin{array}{l}\text { ACDF (without } \\
\text { drainage) Group }\end{array}$ & $\begin{array}{c}\text { Test } \\
\text { Value }\end{array}$ & $P$ \\
\hline & $(\mathrm{N}=45)$ & $(\mathrm{N}=48)$ & & \\
\hline Operation time (min) & $58.22 \pm 4.39$ & $56.23 \pm 4.94$ & 1.226 & 0.228 \\
\hline $\begin{array}{l}\text { Intraoperative blood loss } \\
\text { (ml) }\end{array}$ & $13.24 \pm 2.99$ & $13.15 \pm 2.99$ & 0.104 & 0.917 \\
\hline Hospital stay (d) & $8.59 \pm 1.28$ & $7.03 \pm 1.04$ & 4.564 & $<0.001$ \\
\hline $\begin{array}{l}\text { Postoperative drainage } \\
\text { volume (ml) }\end{array}$ & $3.41 \pm 0.96$ & l & I & l \\
\hline Fever (n) & $2(4.4 \%)$ & $3(6.3 \%)$ & $\mathrm{C} \square=0.149$ & 0.670 \\
\hline \multicolumn{5}{|l|}{ Incision infection (n) } \\
\hline Superficial infection & $1(2.2 \%)$ & $2(4.2 \%)$ & $\mathrm{C} \square=0.281$ & 0.596 \\
\hline Deep infection & 0 & 0 & I & 1.000 \\
\hline $\begin{array}{l}\text { Rate of incision healing } \\
(\%)\end{array}$ & $100 \%$ & $100 \%$ & l & 1.000 \\
\hline
\end{tabular}

\section{Clinical outcome}

The JOA scores in the ACDF (with drainage) and ACDF (without drainage) groups significantly increased from $8.68 \pm 1.31$ and $8.31 \pm 1.22$ before the operation to $15.54 \pm 0.80$ and 15.28 \pm 0.9412 months after the operation, respectively $\left({ }^{*} P=0.000,{ }^{* *} P=0.000\right)$; the VAS scores between the two groups significantly decreased from $6.24 \pm 1.04$ and $6.13 \pm 0.86$ before the operation to $1.41 \pm 0.50$ and $1.49 \pm 0.51$ at the final follow-up, respectively ( $P=0.000,[=0.000$ ); and the NDI scores between the two groups significantly decreased from $12.76 \pm 1.96$ and $12.49 \pm 1.89$ preoperatively to $3.08 \pm 0.76$ and $3.10 \pm 0.9112$ months after the operation, respectively $\left({ }^{\varphi} P=0.000,{ }^{\varphi \varphi} P=0.000\right)$. In terms of the JOA scores, VAS scores and NDI scores, no significant intergroup difference was found preoperatively and postoperatively at any time point $(P>0.05)$. In addition, there were significantly difference between the preoperative and postoperative JOA scores, VAS scores and NDI scores in each group (Table 3). 
Table 3 Clinical outcomes between the two groups

\begin{tabular}{|c|c|c|c|c|}
\hline \multirow[t]{2}{*}{ Variable } & $\begin{array}{l}\text { ACDF (with drainage) } \\
\text { Group }\end{array}$ & $\begin{array}{l}\text { ACDF (without drainage) } \\
\text { Group }\end{array}$ & \multirow[t]{2}{*}{$\begin{array}{c}\text { Test } \\
\text { Value }\end{array}$} & \multirow[t]{2}{*}{$P$} \\
\hline & $(\mathrm{N}=45)$ & $(\mathrm{N}=48)$ & & \\
\hline \multicolumn{5}{|l|}{ JOA scores } \\
\hline Preoperative & $8.68 \pm 1.31$ & $8.31 \pm 1.22$ & 0.921 & 0.363 \\
\hline $\begin{array}{c}\text { Postoperative } 3 \\
\text { months }\end{array}$ & $13.24 \pm 1.28$ & $13.21 \pm 1.36$ & 0.046 & 0.964 \\
\hline $\begin{array}{c}\text { Postoperative } 6 \\
\text { months }\end{array}$ & $14.62 \pm 1.06$ & $14.59 \pm 1.04$ & 0.120 & 0.905 \\
\hline $\begin{array}{c}\text { Postoperative } 12 \\
\text { months }\end{array}$ & $15.54 \pm 0.80^{*}$ & $15.28 \pm 0.94^{\star *}$ & 0.864 & 0.393 \\
\hline \multicolumn{5}{|l|}{ VAS scores } \\
\hline Preoperative & $6.24 \pm 1.04$ & $6.13 \pm 0.86$ & 0.363 & 0.719 \\
\hline $\begin{array}{c}\text { Postoperative } 3 \\
\text { months }\end{array}$ & $1.95 \pm 0.71$ & $2.23 \pm 0.71$ & 1.231 & 0.226 \\
\hline $\begin{array}{c}\text { Postoperative } 6 \\
\text { months }\end{array}$ & $1.65 \pm 0.59$ & $1.77 \pm 0.67$ & 0.559 & 0.579 \\
\hline $\begin{array}{c}\text { Postoperative } 12 \\
\text { months }\end{array}$ & $1.41 \pm 0.50 \square$ & $1.49 \pm 0.51$ & 0.490 & 0.627 \\
\hline \multicolumn{5}{|l|}{ NDI scores } \\
\hline Preoperative & $12.76 \pm 1.96$ & $12.49 \pm 1.89$ & 0.430 & 0.670 \\
\hline $\begin{array}{c}\text { Postoperative } 3 \\
\text { months }\end{array}$ & $4.76 \pm 0.95$ & $4.74 \pm 0.85$ & 0.073 & 0.942 \\
\hline $\begin{array}{c}\text { Postoperative } 6 \\
\text { months }\end{array}$ & $3.41 \pm 0.83$ & $3.59 \pm 0.88$ & 0.639 & 0.527 \\
\hline $\begin{array}{c}\text { Postoperative } 12 \\
\text { months }\end{array}$ & $3.08 \pm 0.76^{\varphi}$ & $3.10 \pm 0.91^{\varphi \varphi}$ & 0.069 & 0.946 \\
\hline
\end{tabular}

The corresponding $P$ values of the JOA scores, VAS scores and NDI scores 12 months postoperatively in the two groups compared with the preoperative scores were as follows: ${ }^{*} P=0.000,{ }^{* *} P=0.000,{ }^{\square} P=0.000,{ }^{\square} P=0.000$, ${ }^{\varphi} P=0.000,{ }^{\varphi \varphi} P=0.000$

\section{Short-term complications}

In the ACDF (with drainage) group, a total of 4 (8.9\%) patients developed postoperative complications, including hoarseness ( 2 patients) and dysphagia ( 2 patients, Table 4 ). In the ACDF (without drainage) group, the postoperative complications included hoarseness (3 patients) and dysphagia (2 patients); there were 5 (10.4\%) patients who showed postoperative complications. After the chi-square test, there was no significant difference in the incidence of postoperative complications between the two groups $(p>0.05)$. The 
symptoms of hoarseness and dysphagia in both groups disappeared within 2 months. In addition, there were no symptomatic epidural hematomas in either group after surgery.

Table 4 Summary of short-term complications of patients in the two groups

\section{Variable}

ACDF (with drainage) ACDF (without drainage)

Group
Group

$(\mathrm{N}=48)$

\begin{tabular}{|c|c|c|c|}
\hline $\begin{array}{l}\text { Symptomatic epidural } \\
\text { hematoma }\end{array}$ & 0 & 0 & 1.000 \\
\hline Hoarseness & $2(4.4 \%)$ & $3(6.3 \%)$ & $\mathrm{C} \square=0.1490 .700$ \\
\hline Dysphagia & $2(4.4 \%)$ & $2(4.2 \%)$ & $C \square=0.0040 .947$ \\
\hline Total & $4(8.9 \%)$ & $5(10.4 \%)$ & $\mathrm{C} \square=0.0620 .803$ \\
\hline
\end{tabular}

\section{Discussion}

Anterior cervical surgery is a common procedure for the treatment of cervical spondylosis; the procedure is characterized by a small level of surgical trauma, it is performed directly to decompress the pressurizer, and it effectively corrects cervical lordosis $[12,13]$. However, early postoperative complications, such as dysphagia, hoarseness, epidural hematoma and nerve injury, easily occur in the local anterior cervical vertebrae, which have a complicated anatomy [14]. According to relevant literature reports, the incidence of short-term complications is between $7 \%$ and $27 \%$ [15]. Among them, epidural hematoma is the most serious complication of the anterior cervical approach, followed by dyspnea of the compressed trachea and severe asphyxia, which can all lead to or aggravate the symptoms of spinal cord compression [16]. Therefore, almost all patients in clinics choose to undergo drainage placement after the anterior cervical approach to prevent postoperative epidural hematoma and avoid spinal cord compression or infection of the incision $[3,4]$. However, studies have shown that whether drainage is 
placed has no significant effect on site infection, epidural hematoma, rupture or reoperation, and whether drainage placement can reduce the incidence of postoperative incision infection in the spine remains controversial $[5,17,18]$. For single-level anterior decompression and internal fixation, with the emergence of new built-in materials, the application of microscope-assisted technology, the maturity of surgical methods and the continuous improvements in perioperative management, the postoperative recovery of patients is accelerated, and the rate of complications and volume of drainage continuously decrease. We consider that nondrainage can be attempted with single-level ACDF through clinical observation. Therefore, we prospectively studied the clinical efficacy of postoperative indwelling drainage (control group) and nondrainage (study group) as well as the incidence of complications.

In this study, the JOA scores at the last follow-up (12 months postoperatively) were significantly higher than those before surgery. The VAS scores and NDI scores at the last follow-up were significantly lower than those before surgery, indicating that both scores have significant clinical effects regarding drainage placement. There was no statistically significant difference between the preoperative and postoperative JOA scores, VAS scores, and NDI scores in the two groups, illustrating that the clinical efficacy of drainage placement was the same.

In our study, there was a significant difference between the control group and the study group in terms of the length of hospital stay, indicating that the hospital stay was shorter without drainage than with drainage after surgery. We suggested that the healing of the anterior cervical drainage hole was slower than that of the surgical incision, which delayed the patient's discharge time. When the drainage of the control group was removed, a round hole with a diameter of approximately $4 \mathrm{~mm}$ was left next to the incision, and it was treated with a pressure dressing of sterile gauze. In the study, it was found that the incision completely healed in 8 patients, while the exudation of the drainage tube hole delayed discharge. In addition, the mean postoperative volume of drainage in the control group was $3.68 \pm 0.82 \mathrm{ml}$, and the range was $3 \sim 5 \mathrm{ml}$. The drainage was removed $24 \mathrm{~h}$ after the operation, which also provided clinical evidence for the absence of drainage after the operation. Moreover, no obvious exudate was found in the study group.

Abnormal fever (axillary temperature $\geq 38.5^{\circ} \mathrm{C}$ ) was observed in $2(4.4 \%)$ and $3(6.3 \%)$ patients in the control and study groups, respectively, and the difference was not statistically significant. A postoperative axillary temperature $\geq 38.5^{\circ} \mathrm{C}$ suggested the possibility of infectious fever. After treatment with intravenous antibiotics, the blood culture and urine culture results were combined, and the temperature of both groups decreased to normal within 3 days (axillary temperature range: $36.0^{\circ} \mathrm{C} \sim 37.4^{\circ} \mathrm{C}$ ). However, according to the differences between individuals, it was not ruled out that the presence of fever was caused by postoperative heat absorption and allograft rejection [19]. 
The incidence of incision infection in the control group and the study group was $2.2 \%$ and $4.2 \%$, respectively, and the difference was not statistically significant. A study by Chandratreya et al. [20] also showed that there was no significant correlation between wound infection and drainage indwelling based on evidence-based medicine. Walid et al. [21] studied 402 patients undergoing lumbar fusion and found no significant correlation between drainage placement and postoperative wound infection. This result is consistent with the results of our study. On the one hand, drainage can draw out hematoceles in the incision and reduce the tension of the incision; on the other hand, drainage placement can increase the risk of incision infection because drainage is retained in the body as foreign matter and increases the number of superficial incisions needed. The longer the indwelling drainage time is, the higher the infection rate of incision [22]. Although there was no statistically significant difference in the incidence of incision infection between the two groups, the incidence of the study group was higher than that of the control group. We found that there were more instances of hematocele in the incision in the study group than in the control group; in addition, the incision tension was relatively larger, and the surface environment of the surgical incision was more moist, which might more easily lead to superficial incision infection. However, further large-scale prospective studies are needed to confirm these results because the sample size of this study was limited. In this study, after conservative treatment with incision dressings and intravenous infusion of antibiotics, the superficial incision infections of both groups improved and healed well.

In our study, no cases of symptomatic epidural hematoma were observed. According to Amiri AR [16] and Aono $\mathrm{H}$ et al. [3], the incidence of epidural hematoma after spinal surgery was $0.22 \sim 0.41 \%$, and the incidence of epidural hematoma after surgery via the anterior cervical approach was $0.21 \%$. The incidence rate is closely related to the surgical operation. Domestic literature reports that the incidence of epidural hematoma with the anterior cervical approach is $0.23 \%$ [23]. The main causes of epidural hematoma are 1 . incomplete operations, such as cases where small blood vessel hemostasis is not complete intraoperatively and subcutaneous capillaries are injured during the suturing of incisions; 2. Insufficient preoperative preparation, for example, if coagulopathy is not noticed before surgery or anticoagulant and antiplatelet drugs are not discontinued; 3. unsatisfactory perioperative blood pressure and blood glucose control; and 4. excessive neck movement after surgery, upper respiratory infection, cough, etc. [24]. These factors easily lead to bleeding. Therefore, we routinely performed decompression and intraoperative hemostasis under the microscope, which is a sophisticated procedure during surgery, to strengthen the perioperative management of patients so that the incidence of symptomatic epidural hematoma with the anterior cervical approach remained low.

For the short-term complications of hoarseness and dysphagia, there was no significant difference between the two groups. This suggests that there is no correlation between whether indwelling drainage is placed and the occurrence of hoarseness and dysphagia. 
Postoperative dysphagia and hoarseness in patients who undergo the anterior cervical approach are mainly due to injury of the pharyngeal wall due to tracheal intubation, resulting in laryngeal edema, excessive traction of the trachea and esophagus during the operation, and injury of the superior and recurrent laryngeal nerves [14,25]. The symptoms of dysphagia and hoarseness were alleviated within 2 months, and there were no related symptoms at the 3-month follow-up.

Due to the development of medical practice and the improvements in surgical techniques, single-level ACDF has a short operation time; results in relatively small levels of surgical trauma, intraoperative blood loss, and postoperative drainage; and has a low incidence of short-term postoperative complications, such as symptomatic epidural hematoma [14]. In addition, surgeons should perform adequate preoperative preparation, improve preoperative examinations, and actively address the comorbidities that may cause postoperative bleeding and infection. For example, for patients with hypertension, preoperative blood pressure should be controlled within a basically normal range. Strict control of blood glucose in diabetic patients has shown that blood glucose $>6.9 \mathrm{mmol} / \mathrm{L}$ preoperatively and blood glucose $>11.1 \mathrm{mmol} / \mathrm{L}$ postoperatively are independent risk factors for incision infection [26]. Intraoperative fine manipulation, such as the use of microscope-assisted techniques or the wearing of a head-mounted magnifying glass [27-29], are conducive for reducing neurovascular injury and protecting soft tissues. In addition, bipolar coagulation is routinely used for intraspinal manipulation to reduce injury and bleeding [30,31]. Additionally, severe cough or vomiting after surgery should be prevented in patients. Moreover, attention should be paid to fixation of the neck when moving the patient in order to prevent excessive neck movement, which may lead to bleeding. Our study shows that single-level ACDF can be performed without drainage placement, as long as we strengthen the perioperative management and intraoperative standardized, fine operation. However, whether indwelling drainage should be placed after double or multisegment ACDF requires further study.

In addition, there are some limitations in this study. First, the sample size was limited, and further large-scale studies are needed to evaluate the complications of symptomatic epidural hematoma, surgical site infection, and postoperative fever. Moreover, the nutritional factors affecting postoperative incision healing were not considered.

\section{Conclusions}

The safety and clinical efficacy of drainage placement and nondrainage after single-level ACDF are consistent; in addition, nondrainage can shorten the length of hospital stay and reduce associated expenses. 


\section{Declarations}

\section{Abbreviations}

ACDF: Anterior cervical discectomy with fusion and plating; JOA: Japanese Orthopaedic Association; VAS: Visual Analogue Scale; NDI: Neck Dysfunction Index; ERAS: Enhanced recovery after surgery; BMI: Body mass index; DVT: Deep venous thrombosis;

Department: 1.The Orthopaedic Surgery, the First Affiliated Hospital of Zhengzhou University, Zhengzhou, China. 2. Neurosurgery, University of California San Francisco, California San Francisco, USA.

Correspondence to: Yilin Liu, MD, Department of Orthopaedic Surgery, the First Affiliated Hospital of Zhengzhou University, 1 Jianshe East Road, Zhengzhou 450052, China. Email: zzu0101@126.com

\section{Ethics approval and consent to participate}

This study was approved by The Ethics Committee of The First Affiliated Hospital of Zhengzhou University. Written informed consent to participate in the study was obtained from each participant.

\section{Consent for publication}

Not applicable.

\section{Availability of data and materials}

The datasets used and/or analysed during the current study are available from the corresponding author on reasonable request. 
The authors declare that they have no competing interests.

\section{Funding}

No funds were received in support of this work.

\section{Authors' contributions}

PL was responsible for conception, design, data analysis, writing and editing of the manuscript. DC was responsible for data analysis, writing and editing of the manuscript, LW was responsible for data analysis and editing of the manuscript, YW was responsible for conception, design, data analysis and editing of the manuscript. GZ was responsible for conception, design, data analysis and editing of the manuscript. SZ made substantial contributions to manuscript revising. YZ made substantial contributions to manuscript revising. TR made substantial contributions to manuscript revising. YX made substantial contributions to manuscript revising. LS made substantial contributions to manuscript revising. YL made substantial contributions to study design, acquisition, analysis and interpretation of data, and involved in drafting the manuscript and revising it critically for important intellectual content. All authors read and approved the final manuscript.

\section{Acknowledgements}

Not applicable.

\section{References}

[1] Grochulla F. Anterior Cervical Discectomy and Fusion. J spine. 2012;13(3):1023-5. https://doi.org/10.1007/978-3-642-22682-3_19

[2] Chang S W, Kakarla U K, Maughan P H, et al. Four-level anterior cervical discectomy and fusion with plate fixation: radiographic and clinical results. J Neurosurgery. 2010;66(4):639-46. https://doi.org/10.1227/01.NEU.0000367449.60796.94

[3] Aono $\mathrm{H}$, Ohwada $\mathrm{T}$, Hosono $\mathrm{N}$, et al. Incidence of postoperative symptomatic epidural hematoma in spinal decompression surgery. J Neurosurg Spine. 2011;15(2):202-5. https://doi.org/10.3171/2011.3.SPINE10716 
[4] Von Eckardstein, Dohmes JE, Rohde V. Use of closed suction devices and other drains in spinal surgery: results of an online, Germany-wide questionnaire. J Eur Spine.

2016;25(3):708-15. https://doi.org/10.1007/s00586-015-3790-8

[5] Louw A, Diener I, Landers MR, et al. Three-year follow-up of a randomized controlled trial comparing preoperative neuroscience education for patients undergoing surgery for lumbar radiculopathy. J Spine Surg. 2016;2(4):289-98.

https://doi.org/10.21037/jss.2016.12.04

[6] Park JH, Ahn Y, Choi BS, et al. Antithrombotic effects of aspirin on 1- or 2-level lumbar spinal fusion surgery: a comparison between 2 groups discontinuing aspirin use before and after 7 days prior to surgery. Spine. 2013;38(18): 1561-5.

https://doi.org/10.1097/BRS.0b013e31829a84d2

[7] Sheehy AM, Gabbay RA. An overview of preoperative glucose evaluation, management and perioperative impact. J Diabetes Sci Technol. 2009;3(6):1261-9.

https://doi.org/10.1177/193229680900300605

[8] Dutton RP. Controlled hypotension for spinal surgery. J Eur Spine. 2004;13 Suppl 1:S66S71. https://doi.org/10.1007/s00586-004-0756-7

[9] Albertin A, La Colla L, Gandolfi A, et al. Greater peripheral blood flow but less bleeding with propofol versus sevoflurane during spine surgery: a possible physiologic model?. Spine. 2008;33(18):2017-22. https://doi.org/10.1097/brs.0b013e31817e0405

[10] Degoute CS, Ray MJ, Manchon M, et al. Remifentanil and controlled hypotension; comparison with nitroprusside or esmolol during tympanoplasty. J Can Anaesth. 2001;48(1):20-27. https://doi.org/10.1007/BF03019809

[11] Hillard V H , Apfelbaum R I . Surgical management of cervical myelopathy: indications and techniques for multilevel cervical discectomy. J Spine Journal. 2006;6(6):S242-S51. https://doi.org/10.1016/j.spinee.2006.05.005

[12] Lee S E, Jahng T A, Kim H J. Correlation between cervical lordosis and adjacent segment pathology after anterior cervical spinal surgery. J European Spine Journal. 2015;24(12):2899-909. https://doi.org/10.1007/s00586-015-4132-6

[13] Tannous O, Jazini E, Ludwig S C. Anterior surgical treatment for cervical spondylotic myelopathy. J Seminars in Spine Surgery. 2014;26(2):73-80.

https://doi.org/10.1053/j.semss.2014.05.004

[14] Nanda A, Sharma M , Sonig A , et al. Surgical Complications of Anterior Cervical Diskectomy and Fusion for Cervical Degenerative Disk Disease: A Single Surgeon's 
Experience of 1576 Patients. J World Neurosurgery. 2014;82(6):1380-7.

https://doi.org/10.1016/j.wneu.2013.09.022

[15] Smith JS, Fu KM, Polly DW, et al. Complication rates of three common spine procedures and rates of thromboembolism following spine surgery based on 108, 419 procedures: a report from the Scoliosis Research Society Morbidity and Mortality Committee. J Spine. 2010;35(24):2140-9. https://doi.org/10.1097/BRS.0b013e3181cbc8e7

[16] Amiri A R, Fouyas I P, Cro S, et al. Postoperative spinal epidural hematoma (SEH): incidence, risk factors, onset and management. J The Spine Journal. 2013;13(2):134-40. https://doi.org/10.1016/j.spinee.2012.10.028

[17] Chimenti P, Molinari R. Post-operative spinal epidural hematoma causing American Spinal Injury Association B spinal cord injury in patients with suction wound drains. J Spinal Cord Med. 2013;36(3):213-9. https://doi.org/10.1179/2045772312Y.0000000070

[18] Awad JN, Kebaish KM, Donigan J, et al. Analysis of the risk factors for the development of post -operative spinal epidural haematoma. J Bone Joint Surg Br. 2005;87(9):1248-52. https://doi.org/10.1302/ 0301-620X.87B9.16518

[19] Walid M S, Woodall M N, Nutter J P, et al. Causes and Risk Factors for Postoperative Fever in Spine Surgery Patients. J Southern medical journal. 2009;102(3):283-6. https://doi.org/10.1097/SMJ.0b013e31819676a4

[20] Chandratreya A, Giannikas K, Livesley P. To drain or not drain: literature versus practice. J R Coll Surg Edinb. 1998;43(6):404-6. https://doi.org/10.1007/s10620-013-2633-X

[21] Walid MS, Abbara M, Tolaymat A, et al. The role of drains in lumbar spine fusion. J World Neurosurg. 2012; 77(2):564-8. https://doi.org/10.1016/j.wneu.2011.05.058

[22] Manian FA, Meyer PL, Setzer J, et al. Surgical site infections associated with methicillin-resistant staphylococcus aureus: do postoperative factors play a role. J Clin Infect Dis. 2003;36(7): 863-8. https://doi.org/ 10.1086 / 368195

[23] Li J F, Hou T S, Li M, et al. Spinal epidural hematom a follow anterior cervical corpectomy: risk factors and precautions. Chin J Orthop. 2017;28(6):497-500. https://doi.org/10.3321/j.issn:0253-2352.2008.06.013

[24] Schroeder G D, Hilibrand A S, Arnold P M, et al. Epidural Hematoma Following Cervical Spine Surgery. Global Spine Journal. 2017;7(1):S120-6.

https://doi.org/10.1177/2192568216687754

[25] Baron E, Soliman A M, Gaughan J P. Dysphagia, hoarseness, and unilateral true vocal fold motion impairment following anterior cervical diskectomy and fusion. J Ann Otol 
Rhinol Laryngol. 2003;112(11):921-6. https://doi.org/10.1177/000348940311201102

[26] Olsen MA, Nepple JJ, Riew KD, et al. Risk factors for surgical site infection following orthopaedic spinal operations. J Bone Joint Surg Am. 2008;90(1): 62-9. https://doi.org/10.2106/JBJS.F.01515

[27] Damodaran O, Lee J, Lee G. Microscope in modern spinal surgery: advantages, ergonomics and limitations. ANZ Surg. 2013;83(4):211-4.

https://doi.org/10.1111/ans.12044

[28] Basques BA, Golinvaux NS, Bohl DD, et al. Use of an operating microscope during spine surgery is associated with minor increases in operating room times and no increased risk of infection. Spine. 2014;39(22): 1910-6.

https://doi.org/10.1097/BRS.0000000000000558

[29] Adogwa O, Elsamadicy A, Reiser E, et al. Comparison of surgical outcomes after anterior cervical discectomy and fusion: does the intra-operative use of a microscope improve surgical outcomes. J Spine Surg. 2016;2(1): 25-30.

https://doi.org/10.1016/j.spinee.2015.07.364

[30] Barrett SL, Vella JM, Dellon AL. Historical development of bipolar coagulation. Microsurgery. 2010;30(8): 667-9. https://doi.org/10.1002/micr.20815

[31] Bulsara KR, Sukhla S, Nimjee SM. History of bipolar coagulation. Neurosurg Rev. 2006;29(2):93-6. https://doi.org/10.1007/s10143-005-0012-6 